Military Technical College

Kobry El-Kobbah,

Cairo, Egypt

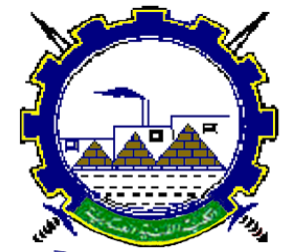

I.C.E.E.2016 $8^{\text {th }}$ International Conference

on

Chemical \& Environmental

Engineering

$19-21$ April 2016

\title{
RA-2
}

\section{Characterization of gamma-irradiated plasticized starch (PLST)/carboxymethyl cellulose (CMC) blends and their antimicrobial properties}

Magdy M. H. Senna1, *, Hussein E. Ali 1, Abo El-Khair B. Mostafa2, Abdel Wahab M. El-Naggar

\begin{abstract}
Plasticized starch (PLST)/carboxymethyl cellulose (CMC) blends were fabricated at different composition ratios in the form of thin films via solution casting. The PLST/CMC films were exposed to different doses of gamma radiation. The effect of gamma irradiation on the thermal, mechanical and structural morphology properties of the films was investigated. The swelling properties of the PLST/CMC blends increased as the $\mathrm{CMC}$ content increased; however, the swelling was decreased at higher irradiation doses. The PLST/CMC blends exhibited lower thermal stability than pure PLST; however, a slight increase in thermal stability was observed with an increasing irradiation dose. Mechanical testing revealed that the tensile strength and elongation at break increased with an increasing irradiation dose. The results indicated that the gammairradiated PLST/CMC/chitosan blends had higher antimicrobial properties than the unirradiated blends.
\end{abstract}

\section{Keywords:}

Plasticized Starch; Blends; Compatibilizers; Gamm Irradiationetween CMC and PLST

1:Radiation Chemistry Department, National Center for Radiation Research and Technology, B.O. Box 29 Nasr City, Cairo Egypt

2:Chemistry Department, College for Girls, Ain Shams University, Cairo, Egypt 
Military Technical College

Kobry El-Kobbah, Cairo, Egypt

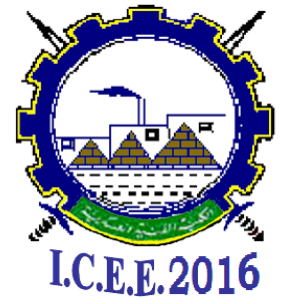

$8^{\text {th }}$ International Conference

on

Chemical \& Environmental Engineering

$19-21$ April 2016

\section{Introduction}

Biodegradable polymers have prompted researchers to synthesize new polymeric types that can be returned to the biological cycle after use. The use of agricultural biopolymers that are easily biodegradable both solves this problem and provides a new potential use for surplus farm production [1]. Over the last few years, interest has increased in biodegradable films and films fabricated from renewable and natural polymers. Watersoluble polysaccharides, such as starch, chitosan, cellulose derivatives, alginate, carrageenan and pectin, can form biodegradable and edible films [2-6]. Numerous studies have analyzed the properties of starch-based films [7-12]. In the absence of additives, a film fabricated from starch is brittle and sensitive to water (hygroscopic). The addition of plasticizers overcomes starch film brittleness and improves the flexibility and extensibility of the film. Occasionally, plasticizers are only used to facilitate polymer processing. Water, oligosaccharides, polyols and lipids are different types of plasticizers that are widely used in hydrocolloid-based films [13]. Generally, there are two approaches to improve these drawbacks (brittleness and water sensitivity). One method is to blend starch with other film forming biodegradable polymers [14]. The mechanical properties and water resistance of blends significantly depend on the biodegradable polymer content. The other method to modify the properties of starch is to replace the hydrophilic $-\mathrm{OH}$ groups with hydrophobic groups via, for example, esterification and etherification. Regardless of the modification methods that are used, the modified starch does not exhibit satisfactory elongation at break and tensile strength due to the glucose ring in the molecular structure of starch and the drastically decreased molecular weight. Moreover, these modified starches are more expensive than other polymers.

Carboxymethyl cellulose (CMC), which is widely used in the pharmaceutical industry, exhibits a significant swelling capacity, non-toxicity, biodegradability, unique reactivation, hydrophilicity and molecular characteristics [15]. Cellulose and its derivatives generally undergo degradation under high-energy radiation. However, radiation crosslinking was observed in a high-concentration solution (paste-like condition) of CMC [16]. Crosslinked CMC is suitable for healthcare products, such as surgical operation mats for the prevention of bedsores.

Radiation technology may serve as a tool for reactive compatibilization [17]. The main advantages of using high-energy radiation with polymer blends are as follows: (a) strong bridges can be formed between macromolecules; (b) the polymer blend (one crosslinkable component and another component less stable against high-energy processing) can be compatibilized by high-energy radiation without the addition of any 
Military Technical College

Kobry El-Kobbah, Cairo, Egypt

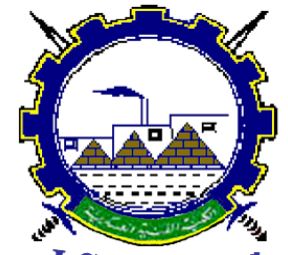

I.C.E.E.2016 $8^{\text {th }}$ International Conference

on

Chemical \& Environmental

Engineering

$19-21$ April 2016

ionomer; and (c) multifunction monomers and/or ionomers can be added to polymer blends to accelerate and increase the degree of crosslinking [18]. The radiation compatibilization of binary systems has been a topic of interest for many years. This technique has been used efficiently and economically to produce new or modified polymers [19]. In our earlier work [20], starch/PVA blends containing chitosan were used as edible food coating films to preserve mango fruits via surface coating. The gammairradiated blend prolonged the storage life from 7 to 15 days. After 15 days, the mango fruit that was treated with gamma-irradiated blends still displayed its initial natural color and maintained its initial ripening state, whereas the untreated fruits were completely damaged.

The present work was undertaken to study the effect of gamma irradiation on the structural properties of polymer blends based on different ratios of plasticized starch (PLST) and CMC. The antimicrobial activity of PLST/CMC/chitosan is also studied. These blends may eventually be used in the film industry as edible packaging materials for food preservation

\section{Experimental}

\subsection{Materials}

The maize starch used throughout this study was supplied by the Egyptian Company for Starch and Glucose, Cairo, Egypt. The CMC used in this study is a laboratory-grade sodium salt in the form of a powder, and it was obtained from the El-Nasr Company for Pharmaceutical Chemicals, Egypt. Low-molecular-weight chitosan with a Brookfield viscosity of 20,000 was obtained from Aldrich Inc., USA.

\subsection{Preparation of PLST}

PLST was prepared by dissolving maize starch in water under continuous stirring and then heating the solution for $1 \mathrm{~h}$ at $95^{\circ} \mathrm{C}$ to obtain a completely gelatinized solution. Subsequently, glycerol (20 wt $\%$ based on the weight of the starch powder) was added.

\subsection{Preparation of PLST/CMC blends}

PLST/CMC films of various compositions were prepared. The required amount of CMC dissolved in hot water was added to the gelatinized starch solution during stirring. Films 
Military Technical College

Kobry El-Kobbah, Cairo, Egypt

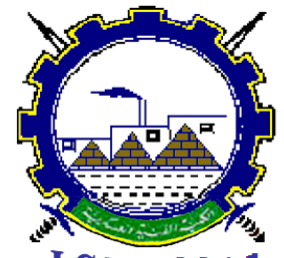

I.C.E.E.2016 $8^{\text {th }}$ International Conference

on

Chemical \& Environmental

Engineering

$19-21$ April 2016

were obtained by casting the unirradiated or irradiated blend solutions on plates and allowing them to air-dry. The films were dried in a vacuum oven at $80^{\circ} \mathrm{C}$ for $4 \mathrm{~h}$ to remove residual water.

\subsection{Gamma irradiation}

Irradiation with the required doses was performed using a Co-60 gamma cell at a dose rate of $4.8 \mathrm{kGy} / \mathrm{h}$. The gamma cell facility was installed at the National Center for Radiation Research and Technology, Cairo, Egypt. The exposure time was adjusted to achieve the required absorbed doses.

\subsection{Thermogravimetric analysis (TGA)}

TGA thermograms were obtained using a Shimadzu instrument (Kyoto, Japan) with a heating rate of $10^{\circ} \mathrm{C} / \mathrm{min}$ under flowing nitrogen $(20 \mathrm{ml} / \mathrm{min})$ from room temperature to $500^{\circ} \mathrm{C}$.

\subsection{Differential scanning calorimetry (DSC)}

DSC measurements were performed using a Shimadzu DSC calorimeter (Kyoto, Japan) equipped with a data station.

\subsection{Tensile mechanical properties}

Mechanical testing of the PLST/CMC blends, including the tensile strength and elongation at break points, was performed at room temperature using an Instron machine (model 1195) with a crosshead speed of $5 \mathrm{~mm} / \mathrm{min}$ according to the ASTM D-638 standards.

\subsection{Scanning electron microscopy (SEM)}

The fracture surface morphologies of the different PLST/CMC blends were examined using SEM. SEM micrographs were taken using a JSM-5400 electron microscope, JEOL, Japan. A sputter coater was used to pre-coat conductive gold onto the fracture surfaces before the micrographs were observed at $30 \mathrm{kV}$. 
Military Technical College

Kobry El-Kobbah, Cairo, Egypt

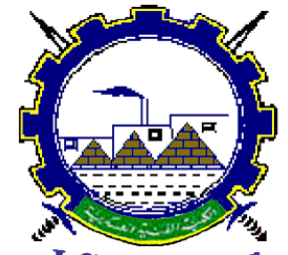

I.C.E.E.2016 $8^{\text {th }}$ International Conference on

Chemical \& Environmental Engineering

$19-21$ April 2016

\subsection{Swelling properties}

The samples were immersed in deionized water for $24 \mathrm{~h}$ at room temperature, quickly dried with filter paper and weighed. The swelling was calculated as follows:

$$
\text { Swelling }(\%)=\left[\left(\mathbf{W}_{\mathrm{s}}-\mathbf{W}_{\mathrm{i}}\right) / \mathbf{W}_{\mathrm{i}}\right] \times \mathbf{1 0 0},
$$

Where

$\mathrm{W}_{\mathrm{s}}$ is the weight of the sample in the swollen state and $\mathrm{W}_{\mathrm{i}}$ is the initial weight of the dry sample.

\subsection{Antibacterial activity}

The antibacterial activity of the PLST/CMC/chitosan blend films against Escherichia coli was evaluated by measuring the optical density of samples incubated at $37^{\circ} \mathrm{C}$. During the incubation, the turbidity of the medium was measured at $650 \mathrm{~nm}$ every $2 \mathrm{~h}$. The activity was also evaluated by determining the inhibition zone.

To eliminate the influence of acids on the antimicrobial activity of the PLST/CMC/chitosan blends, the acetic acid that remained in the composite films was neutralized via exposure to an aqueous solution of $\mathrm{Na}_{2} \mathrm{CO}_{3}\left(0.2 \mathrm{~mol} \mathrm{l}^{-1}\right)$ followed by distilled water.

\section{RESULTS AND DISCUSSION}

\subsection{Swelling properties of PLST/CMC blends}

Fig. 1 shows the swelling behavior in water at $25^{\circ} \mathrm{C}$ for the PLST/CMC blends with different compositions that were exposed to various doses of gamma irradiation. The degree of swelling for all of the blends progressively increased as the CMC content increased. Additionally, the degree of swelling decreased as the irradiation dose increased. This increase in swelling behavior is due to the higher hydrophilic character of CMC relative to that of PLST. The decrease in the degree of swelling with increasing irradiation dose can be explained by plasticized starch chain interaction with CMC chains. The bonding of starch -CMC results in the closing of the voids and spaces between the molecules, thus preventing the penetration of water. 
Military Technical College

Kobry El-Kobbah, Cairo, Egypt

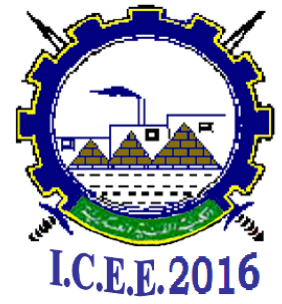

$8^{\text {th }}$ International Conference

on

Chemical \& Environmental Engineering

$19-21$ April 2016

\subsection{TGA}

The average bond dissociation energies of CMC and starch were calculated to be 578 and $385.9 \mathrm{~kJ} / \mathrm{mol}$, respectively. Thus, CMC may have higher thermal stability than starch, and blends of PLST with any amount of CMC will eventually result in higher thermal stability than observed for pure PLST. Additionally, the limited macromolecular chain mobility due to the formation of intermolecular bonds and the association between the macromolecules of the blend components is also expected to increase the thermal stability of the blends.

TGA was used to experimentally investigate the thermal stability of the PLST/CMC blends. Fig. 2 shows the initial TGA thermograms and the thermal reaction decomposition rate (dw/dt) for PLST and the PLST/CMC blends. Table 1 summarizes the percentage weight loss at different decomposition temperatures for the same materials from the corresponding TGA thermograms.

At decomposition temperatures as high as $500^{\circ} \mathrm{C}$, the PLST/CMC blends were thermally less stable than PLST, especially over the temperature range of $50-350^{\circ} \mathrm{C}$. Additionally, the thermal stability of the PLST/CMC blends decreased as the CMC content increased. The situation was reversed for temperatures exceeding $350^{\circ} \mathrm{C}$, at which point the thermal stability of the PLST/CMC blends was higher than that of PLST alone. This behavior is in accordance with that in Mutalik et al. [21].

As shown in Fig. 2, the rate of reaction curves for PLST and the starch/CMC blends displayed a single peak over the entire temperature range. The temperatures corresponding to the maximum rate of reaction $\left(\mathrm{T}_{\max }\right)$ for starch and starch/CMC with different blend ratios are shown in Table 1. The PLST/CMC blends displayed similar $\mathrm{T}_{\max }$ temperatures as PLST, and these temperatures increased as the CMC content increased. These results indicate that starch/CMC is thermally less stable than PLST, especially over the temperature range of $50-350^{\circ} \mathrm{C}$.

Fig. 3 shows the initial TGA thermograms of the PLST/CMC blends after gamma irradiation at doses of 10 and $50 \mathrm{kGy}$. This finding revealed that the starch/CMC composites are more thermally stable than starch, especially at high temperatures. However, the thermal stability of the gamma-irradiated starch/CMC blends was similar to that of the unirradiated blends. As shown in Fig. 3, the rate of reaction curves for the irradiated starch/CMC blends had a single peak over the entire temperature range. The temperatures corresponding to $\mathrm{T}_{\max }$ for the starch/CMC blends before and after gamma 
Military Technical College

Kobry El-Kobbah, Cairo, Egypt

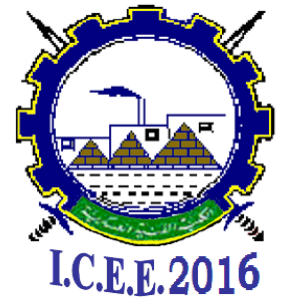

$8^{\text {th }}$ International Conference on

Chemical \& Environmental Engineering

$19-21$ April 2016

irradiation are shown in Table 1. The unirradiated and irradiated starch/CMC blends displayed similar $\mathrm{T}_{\max }$ temperatures as starch.

Based on the TGA study, a few points can be addressed.

(1) Significant weight loss $(20-70 \%)$ occurred in the temperature range of $100-400^{\circ} \mathrm{C}$, with the unirradiated blends exhibiting greater stability outside this temperature range than PLST alone. Over the temperature range of $100-400^{\circ} \mathrm{C}$, the thermal stability of the blends was lower than that of PLST alone, in disagreement with the theoretical calculation based on the average bond dissociation energy of a starch unit and a CMC unit. This result may be explained by the much higher hydrophilicity of CMC than of starch, and the weight loss at temperatures of $\sim 150^{\circ} \mathrm{C}$ is thus greater in $\mathrm{CMC}$ than in PLST. Additionally, the presence of the ether linkage as a weak point (dissociation energy $\sim 72 \mathrm{kCal} / \mathrm{mol}$ ) in the side chain makes the side chain easier to lose after water loss.

(2) The $T_{\max }$ data revealed that the gamma-irradiated blends have similar thermal stability as the unirradiated blends. The rate of reaction curves generally displayed similar trends, in which all of the blends exhibited one maximum, indicating a good distribution between PLST and CMC in the blends. Moreover, a visual observation revealed that all of the PLST/CMC mixture solutions were clear at room temperature and that the films of the blends appeared transparent.

(3) The slight increase in the thermal stability associated with an increase in the irradiation dose can be attributed to the occurrence of oxidative groups in the component, as shown in Scheme 2 [22]. The oxidative groups have a higher bond dissociation energy than the other bonds.

\subsection{DSC}

DSC analysis has proven to be a valuable method for investigating the thermal parameters of polymeric systems. In this study, DSC curves were obtained for both PLST and the PLST/CMC blends, as shown in Figs. 4-5. $\mathrm{T}_{\mathrm{g}}$ was taken as the temperature of the first endothermic peak, which is the enthalpy relaxation of the amorphous part, and $T_{m}$ was taken as the second endothermic peak, which is due to the melting of the crystalline part of the blend. The first transition started at $60^{\circ} \mathrm{C}$ for PLST and ended with an endothermic transition at approximately $100^{\circ} \mathrm{C}$, and the maximum of this peak occurred at $67.5^{\circ} \mathrm{C}$. However, the DSC scans of the glass transition did not display the $\mathrm{T}_{\mathrm{g}}$ of either CMC or PLST but instead exhibited a new single glass transition, which may indicate 
Military Technical College

Kobry El-Kobbah, Cairo, Egypt

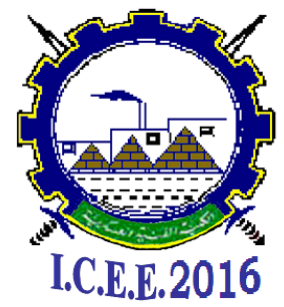

$8^{\text {th }}$ International Conference

on

Chemical \& Environmental Engineering

$19-21$ April 2016

compatibility. The reported glass transition temperatures in the literature for PLST and $\mathrm{CMC}$ are 84 and $150^{\circ} \mathrm{C}$, respectively, depending on the plasticizer that was used and the thermal history of the samples.

The DSC thermograms of the PLST/CMC blends exhibited two endothermic peaks due to the glass transition temperature $\left(\mathrm{T}_{\mathrm{g}}\right)$ and melting temperature $\left(\mathrm{T}_{\mathrm{m}}\right)$ either before or after gamma irradiation. $\mathrm{T}_{\mathrm{g}}$ increased upon the addition of $\mathrm{CMC}$ to starch but decreased as the irradiation dose increased, and $\mathrm{T}_{\mathrm{m}}$ also decreased upon gamma irradiation of the blends. The thermograms of the blends that are depicted in Fig. 5 clearly suggest that the blends have a semi-crystalline nature. These thermograms displayed a $\mathrm{T}_{\mathrm{g}}$ of $88^{\circ} \mathrm{C}$, possibly due to starch, and a $\mathrm{T}_{\mathrm{m}}$ of $224^{\circ} \mathrm{C}$, which may be attributed to the melting of the crystallites that developed due to the incorporation of semi-crystalline CMC into the starch. The blend sample is crystalline in nature, which may be explained by the anionically charged CMC chains folding themselves into the starch matrix, thus forming crystallites due to the extensive hydrogen bonding between the hydroxyl groups of starch and the carboxyl groups of the $\mathrm{CMC}$ macromolecules.

\subsection{Mechanical properties}

The stress-strain test is the most widely used method among mechanical tests. The effect of gamma irradiation on the mechanical properties of the PLST/CMC blends with different compositions was studied. As shown in Figs. 6-8, the tensile mechanical properties of PLST as a blank and of the PLST/CMC blends containing different amounts of $\mathrm{CMC}$ were obtained. From the data, it was found that the break stress and elongation increased as the CMC content and irradiation dose increased.

The increase in the mechanical strain with increasing CMC content was due to CMC retarding the retrogradation process in starch. Additionally, the repulsive force between the anionic charges on the $\mathrm{CMC}$ chains resulted in a space that accommodated a large amount of glycerol, which acts as a plasticizer, thus facilitating bending. Conversely, the improvement in the tensile properties of the PLST/CMC blends after irradiation might be attributed to the formation of hydrogen bonds or to the chemical interaction between free radicals of $\mathrm{CMC}$ and free radicals formed on starch. The probability of the formation of hydrogen bonds between CMC and starch is shown in Scheme 2 [23], which indicates that ester bonds were formed between the hydroxyl groups in the starch branches and the carboxylate groups of CMC. 
Military Technical College

Kobry El-Kobbah, Cairo, Egypt

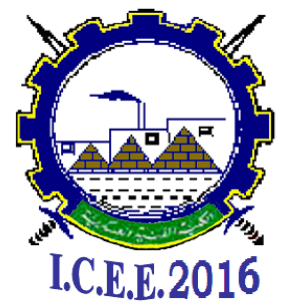

$8^{\text {th }}$ International Conference

on

Chemical \& Environmental Engineering

$19-21$ April 2016

\subsection{SEM}

In compatible blends such as PLST/CMC, the morphology of the blends depends on the phase dispersion and the phase size. Thus, in the PLST/CMC blends, CMC is expected to be the dispersed phase. Figs. 9-10 show the SEM fracture surface micrographs of unirradiated pure PLST and the PLST/CMC blends with different composition ratios before and after gamma irradiation. As shown in Fig. 9, the fracture surface of pure PLST is smooth, and no starch granules occur due to complete gelatinization. However, the SEM micrographs of the unirradiated PLST/CMC blends revealed a different surface morphology in which the surface is smooth and has a different texture. This texture changed as the CMC content increased. The effect of gamma irradiation on the SEM micrographs of the PLST/CMC blends is shown in Fig. 10. The CMC phase appears to become a part of the entire matrix.

\subsection{Antibacterial properties}

Recently, increasing attention has been devoted to developing and testing films with antimicrobial properties to improve food safety and shelf life. Active biomolecules, such as chitosan and its derivatives, play a significant role in the food application area in light of recent contamination outbreaks that were associated with food products and growing concerns regarding the negative environmental impact of currently used packaging materials. The antimicrobial properties of PLST/CMC blend films containing chitosan as an antimicrobial material in a concentration of 5\% were investigated.

The antimicrobial activity of the gamma-irradiated and unirradiated PLST/CMC/chitosan blends was investigated by observing the suppression of $E$. coli growth using the optical density method and by inhibition zone. As shown in Figs. 11-12, the irradiation of the chitosan blends effectively increased the activity and inhibited the growth of E. coli, leading to an inhibition zone around the sample. The inhibition zone increased as the irradiation dose increased.

\section{Conclusions}

Gamma irradiation was found to affect the properties of polymer blends. The swelling properties of PLST/CMC blends increased as the CMC content increased, but the swelling behavior was decreased by higher irradiation doses. The thermal stability of the different blends was lower than that of PLST alone due to the presence of an ether linkage. The slight increase in the thermal stability with increasing irradiation doses was 
Military Technical College

Kobry El-Kobbah, Cairo, Egypt

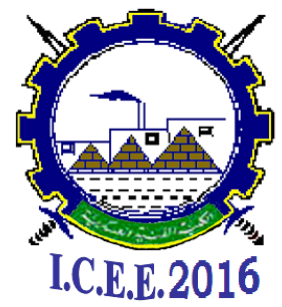

$8^{\text {th }}$ International Conference

on

Chemical \& Environmental Engineering

$19-21$ April 2016

due to the presence of oxidative groups. The mechanical property measurements revealed that the tensile strength and elongation percentage increased with increasing irradiation doses, which may be due to an increase in the adhesion forces between the starch and CMC phases. Finally, analysis of the antimicrobial properties of irradiated blends that contained chitosan demonstrated that the irradiated blends have better properties than the unirradiated blends.

\section{References}

[1] D. F. Parra, C. C. Tadini, P. Ponce, A. B. Lugão., Mechanical properties and water vapor transmission in some blends of cassava starch edible films Carbohydr. Polym., 58(2004), 475.

[2] M. O. Nisperos-Carriedo: Edible coatings and films based on polysaccharides, in Edible Coatings and Films to Improve Food Quality (Eds. J. M. Krochta, E. A. Baldwin, M. O. Nisperos- Carriedo) Technomic Pub. Co, Lancaster, Pa (1994).

[3] J. W. Lawton, Effect of starch type on the properties of starch containing films Carbohydr. Polym., 29 (1996), 203.

[4] J. M. Krochta, C. De Mulder-Johnson, Edible and biodegradable polymer films: challenges and Opportunities, Food Technol., 51 (2) (1997), 61.

[5] M. Fernández-Cervera, J. Heinämäki, K. Krogars, A. C. Jörgensen, M. Karjalainem, A. I. Colarte, J. Yliruusi, Solid-state and mechanical properties of aqueous chitosan-amylose starch films plasticized with polyols, AAPS Pharm SciTech, 5 (1). (2004) 1.

[6] M. A. García, A. Pinotti, M. N. Martino, N. E. Zaritzky. Characterization of composite hydrocolloid films, Carbohydr. Polym., 56 (3) (2004), 339.

[7] J. W. Lawton, G. F. Fanta. Glycerol-plasticized films prepared from starchpoly(vinyl alcohol) mixtures: effect of poly(ethylene-co-acrylic acid) Carbohydr. Polym., 23(1994), 275.

[8] D. Lourdin, G. Della Valle, P. Colonna. Influence of amylose content on starch films and foams Carbohydr. Polym., 27(1995), 261.

[9] I. Arvanitoyannis, C. G. Billiaderis, H. Ogawa, N. Kawasaki, Biodegradable films made from (LDPE), rice starch and potato starch for food packaging applications: Part 1. Carbohydr. Polym., 36 (1998), 89.

[10] M. A. García, M. N. Martino, N. E. Zaritzky. Edible starch films and coatings characterization: scanning electron microscopy, water vapor, and gas permeability, Scanning, 21 (5) (1999), 348.

[11] M.A. García, M. N. Martino, N. E. Zaritzky, Microstructural characterization of plasticized starch-based films, Starch, 52 (4) (2000), 118. 
Military Technical College

Kobry El-Kobbah, Cairo, Egypt

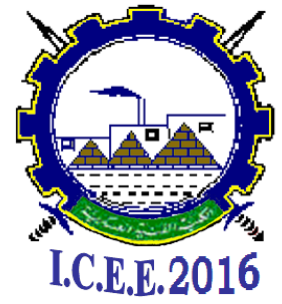

$8^{\text {th }}$ International Conference

on

Chemical \& Environmental Engineering

$19-21$ April 2016

[12] S. Mali, L. S. Sakanaka, F. Yamashita, M. V. E. Grossman. Water sorption and mechanical properties of cassava starch films and their relation to plasticizing effect Carbohydr. Polym., 60 (2005), 283.

[13] B. Cuq, N. Gontard, S. Guilbert. Proteins as agricultural polymers for packaging production, Cereal Chem., 75 (1) (1998), 1.

[14] SD. Zhang, YR Zhang, J. Zhu, XL. Wang, KK Yang, YZ. Wang, Modified corn starches with improved comprehensive properties for preparing thermoplastics, Starch 59, (2007), 258.

[15] Bajpai AK and Shrivastava, In vitro enzymatic degradation kinetics of polymeric blends of crosslinked starch and carboxymethyl cellulose, J., Polym Int, 54(2005), 1524.

[16] Peng J. , Li J. and Wu J., Radiation crosslinking of CMC-Na at low dose and its application as substitute for hydrogel, Radiat. Phys. Chem., 72(5) (2005), 635

[17] M. M. Senna, Y. K. Abdel-Moneam, Y. A. Hussein, A. Alarifi , Effects of Electron Beam Irradiation on the Structure-Property Behavior of Blends Based on LDPE and SEBS Block Copolymers J. Appl. Polym. Sci., 125(2012), 2384.

[18] Chantra T R., Abdulla Z. and Ismail H., Electron Beam Irradiation of EVA/ENR Blend, Polym. Plast. Tech. Eng., 45(4) (2006): 555.

[19] M. M. Senna, S. Salmieri, A. El-naggar, A. Safrany, and M. lacroix, Improving the Compatibility of Zein/Poly(vinyl alcohol) Blends by Gamma Irradiation and Graft Copolymerization of Acrylic Acid, J. Agric. Food Chem., 58(2010), 4470.

[20] M. M. Senna, H. A. El-Shahat, A.M. El-Naggar, Characterization of gamma irradiated plasticized starch/poly (vinyl alcohol) (PLST/PVA) blends and their application as protected edible materials, J Polym Res 18(2011),763.

[21] V.Mutalike, L.S Manjeshwar., Wali A.. Sairamy M., Sreedhar B. , Raju K.V.S., and Aminabhavi T.M, Aqueous-Solution and Solid-Film Properties of Poly(vinyl alcohol), Poly(vinyl pyrrolidone), Gelatin, Starch, and Carboxymethyl cellulose Polymers, Appl. Polym. Sci., 106(2007), 765.

[22] Radoslaw A., Hiroshi M., Naotsugu N., and Fumio Y., Radiation crosslinking of carboxymethylcellulose of various degree of substitution at high concentration in aqueous solutions of natural pH, Rad. Phys. and Chem., 68(2003), 771.

[23] Yue Li, Charles F. Shoemaker, Jianguo Maa, Xueran Shen , Fang Zhong , Paste viscosity of rice starches of different amylose content and carboxymethylcellulose formed by dry heating and the physical properties of their films Food Chemistry 109 (2008) 616-623. 
Military Technical College Kobry El-Kobbah, Cairo, Egypt

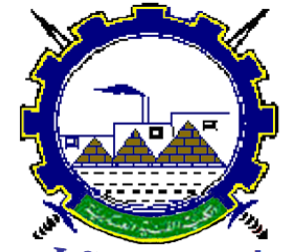

I.C.E.E.2016 $8^{\text {th }}$ International Conference on Chemical \& Environmental Engineering

19-21 April 2016

Table 1: Percentage weight loss of pure PLST and PLST/CMC blends with different composition ratios before and after gamma irradiation at various doses.

\begin{tabular}{|c|c|c|c|c|c|c|c|}
\hline \multirow{2}{*}{$\begin{array}{c}\text { PLST/CMC } \\
\text { blend }\end{array}$} & \multirow{2}{*}{$\begin{array}{l}\text { Dose } \\
(\mathrm{kGy})\end{array}$} & \multicolumn{5}{|c|}{ Weight loss (\%) } & \multirow{2}{*}{$\begin{array}{l}\mathrm{T}_{\max } \\
\left({ }^{\circ} \mathrm{C}\right)\end{array}$} \\
\hline & & $100^{\circ} \mathrm{C}$ & $200^{\circ} \mathrm{C}$ & $300^{\circ} \mathrm{C}$ & $400^{\circ} \mathrm{C}$ & $500^{\circ} \mathrm{C}$ & \\
\hline $\begin{array}{c}\text { PLST } \\
(100 \%)\end{array}$ & 0 & 4.4 & 10.8 & 33.4 & 81.8 & 89.1 & 306 \\
\hline \multirow{3}{*}{$90 \% / 10 \%$} & 0 & 4.1 & 9.5 & 44.5 & 71.0 & 78.1 & 306 \\
\hline & 10 & 5.71 & 8.87 & 50.51 & 67.43 & 74.50 & 296 \\
\hline & 50 & 4.34 & 9.88 & 48.06 & 68.54 & 72.91 & 307 \\
\hline \multirow{3}{*}{$80 \% / 20 \%$} & 0 & 4.7 & 10.7 & 49.7 & 68.6 & 73.9 & 307 \\
\hline & 10 & 7.04 & 13.2 & 53.6 & 73.6 & 77.9 & 307 \\
\hline & 50 & 5.00 & 10.5 & 49.8 & 66.3 & 70.1 & 309 \\
\hline
\end{tabular}


Military Technical College Kobry El-Kobbah, Cairo, Egypt

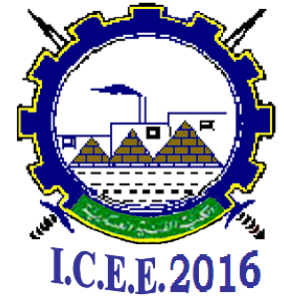

$8^{\text {th }}$ International Conference on

Chemical \& Environmental Engineering

19 - 21 April 2016

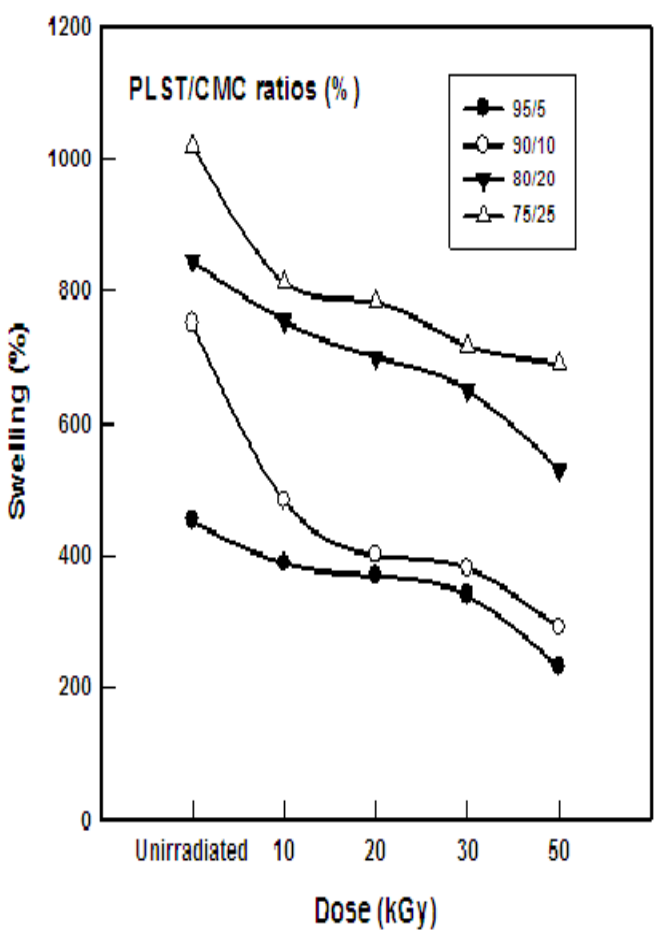

Fig. 1. Effect of irradiation dose on the swelling (\%) of PLST/CMC blends with different composition ratios in water at room temperature $(\%)$.
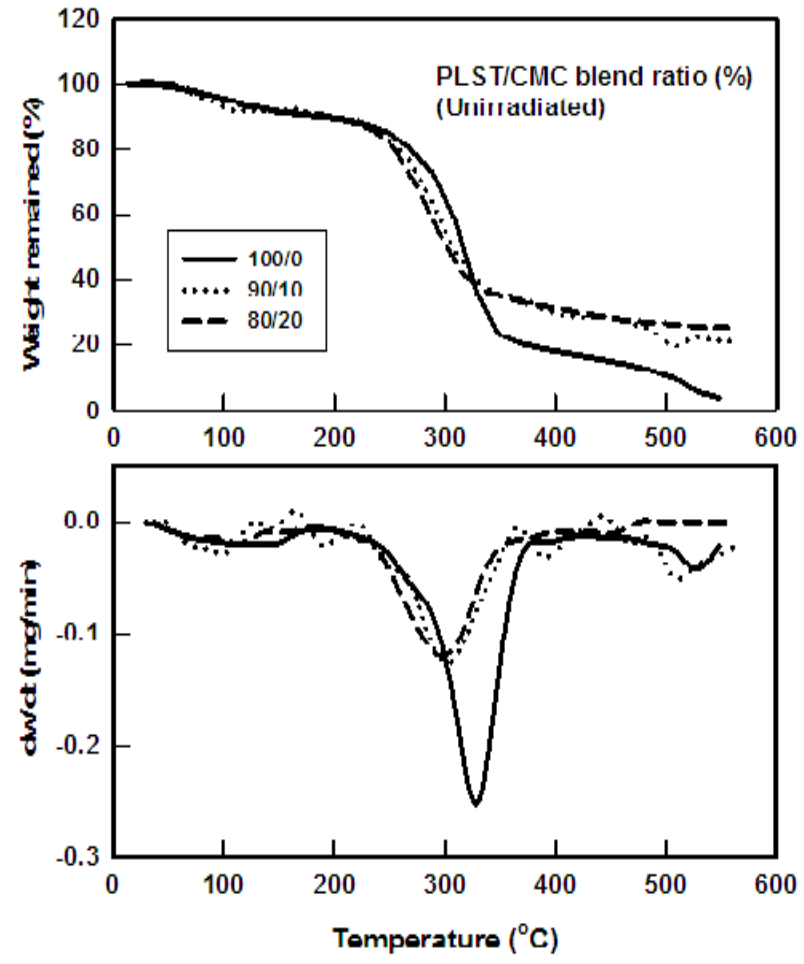

Fig. 2. TGA thermograms and thermal decomposition reaction rates $(\mathrm{dw} / \mathrm{dt})$ of the unirradiated PLST/CMC blends with different composition ratios. 
Military Technical College Kobry El-Kobbah, Cairo, Egypt

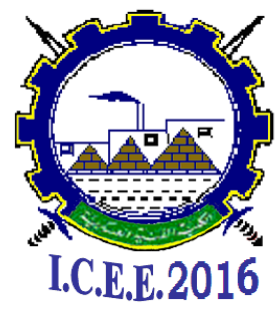

$8^{\text {th }}$ International Conference on

Chemical \& Environmental Engineering

19-21 April 2016
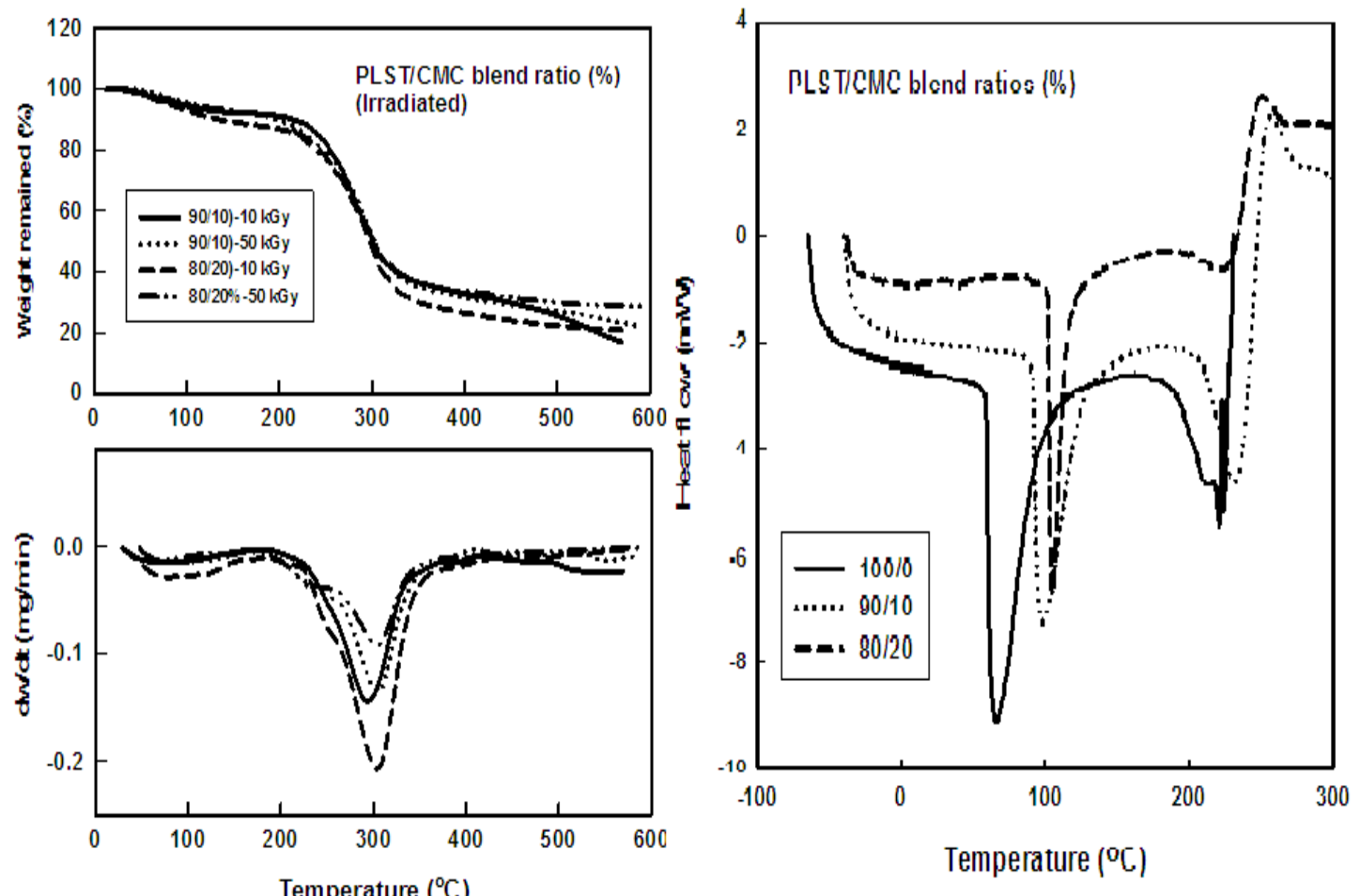

Fig. 3. TGA thermograms and thermal decomposition reaction rates (dw/dt) of the PLST/CMC blends with different composition ratios after exposure to various doses of gamma radiation

Fig. 4. DSC thermograms of the unirradiated PLST/CMC blends with different composition ratios. 
Military Technical College Kobry El-Kobbah, Cairo, Egypt

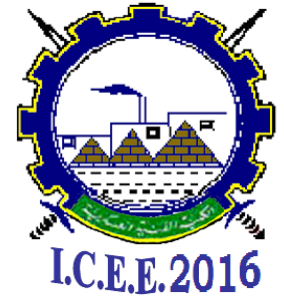

$8^{\text {th }}$ International Conference on Chemical \& Environmental Engineering $19-21$ April 2016

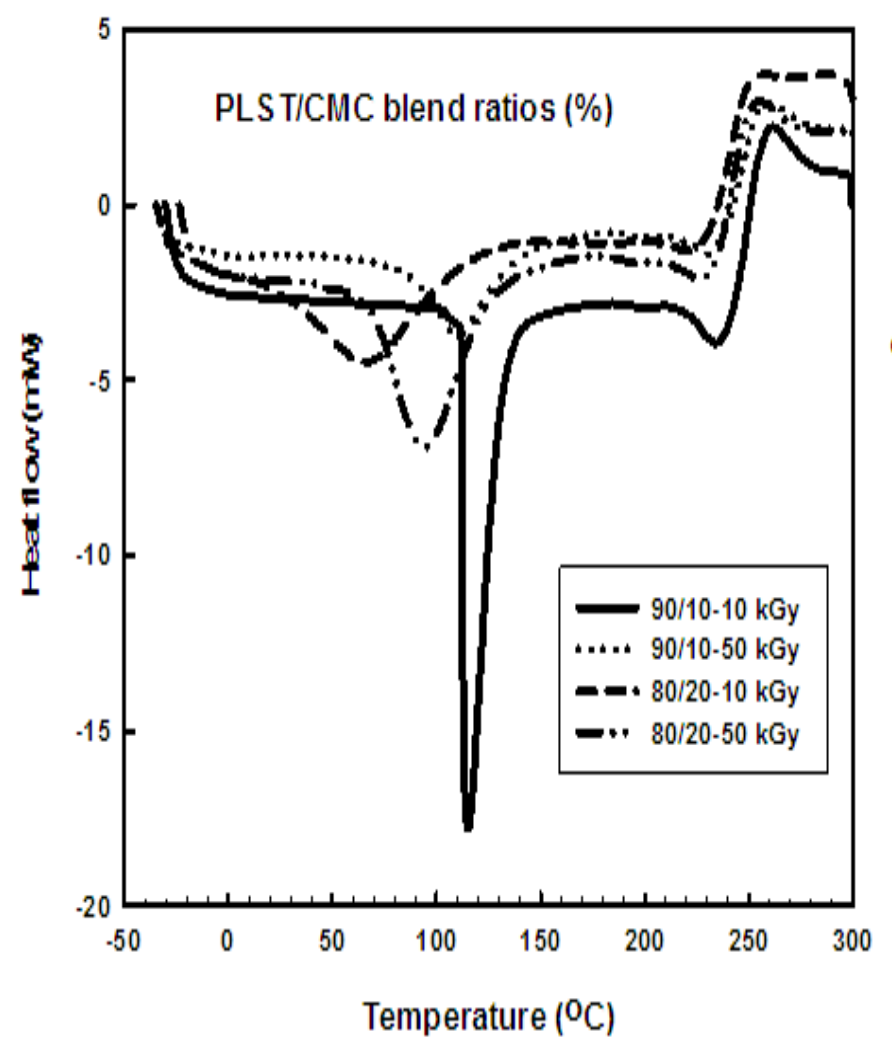

Fig. 5. DSC thermograms of the PLST/CMC blends with different composition ratios exposed to various doses of gamma irradiation.

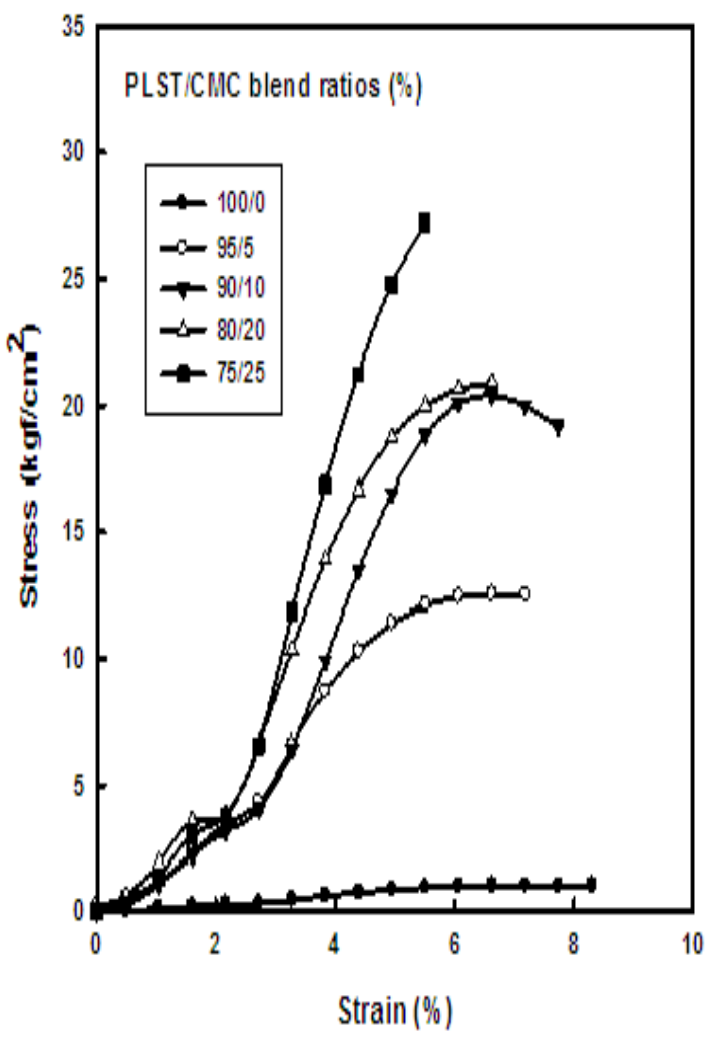

Fig. 6. Stress-strain curves of the unirradiated PLST/CMC blends with different composition ratios. 
Military Technical College Kobry El-Kobbah, Cairo, Egypt

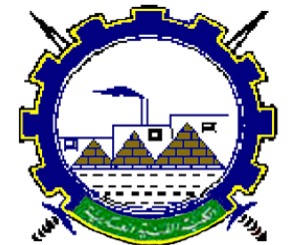

I.C.E.E.2016 $8^{\text {th }}$ International Conference on

Chemical \& Environmental Engineering

$19-21$ April 2016

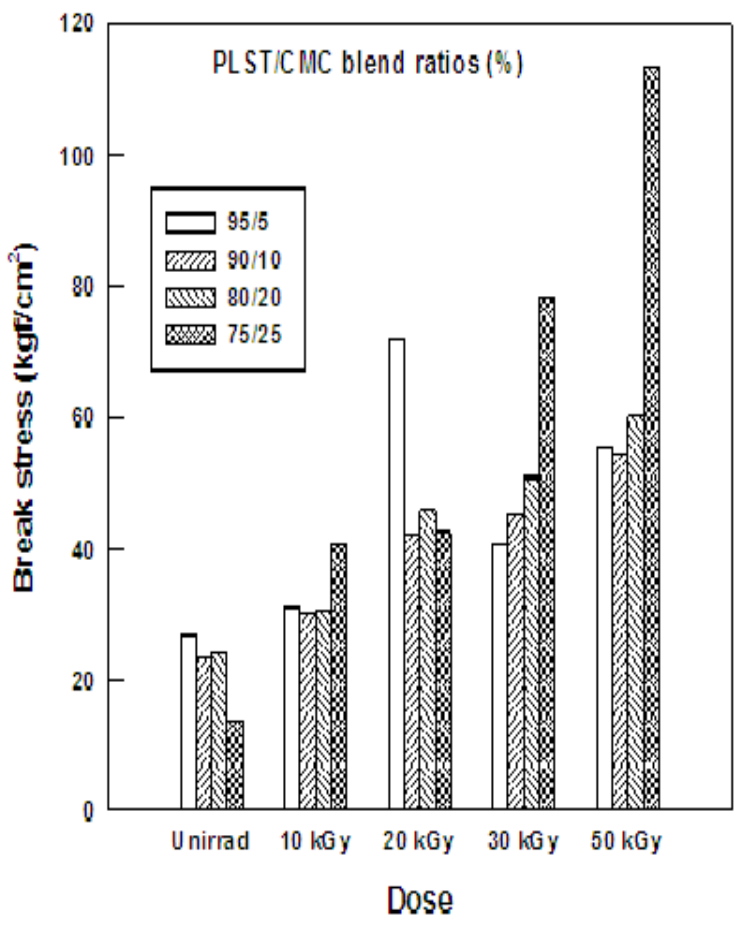

Fig. 7. Break stress of the PLST/CMC blends with different composition ratios exposed to various doses of gamma irradiation.

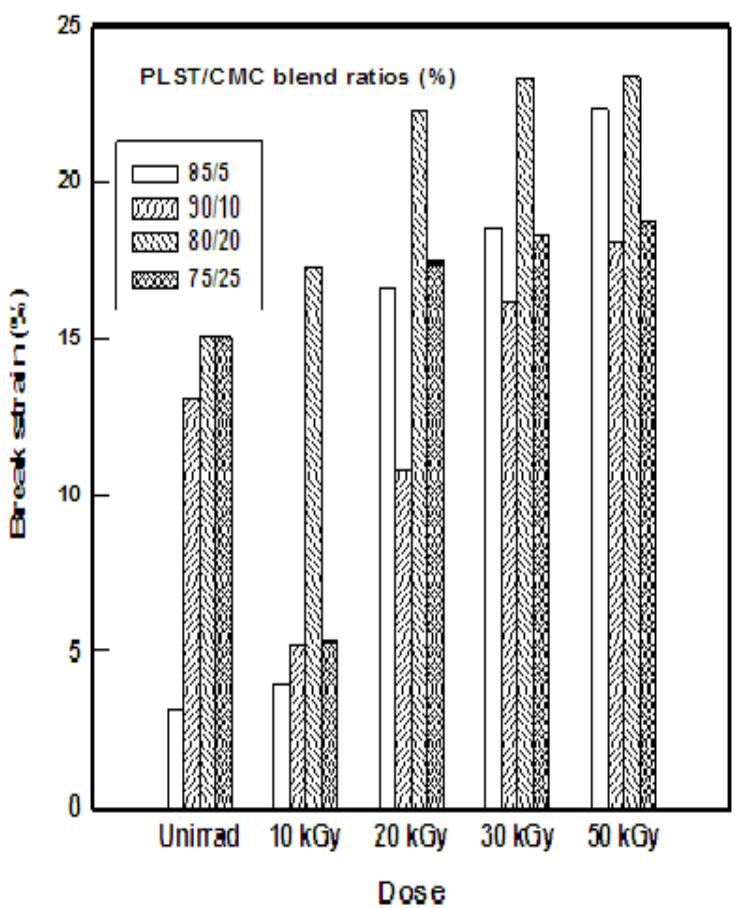

Fig. 8. Break strain of the PLST/CMC blends with different composition ratios exposed to various doses of gamma irradiation. 


\section{RA-2}

Military Technical College Kobry El-Kobbah, Cairo, Egypt

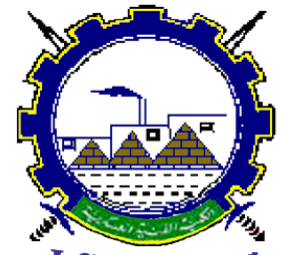

I.C.E.E.2016 $8^{\text {th }}$ International Conference

on

Chemical \& Environmental Engineering

19 - 21 April 2016

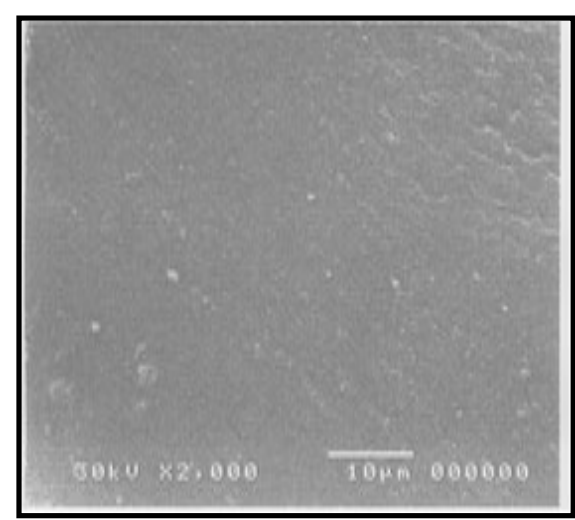

PLST (100\%)

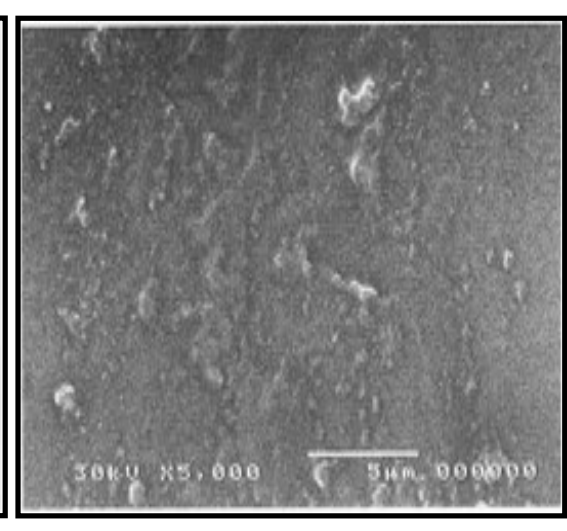

PLST/CMC (90\%/10\%)

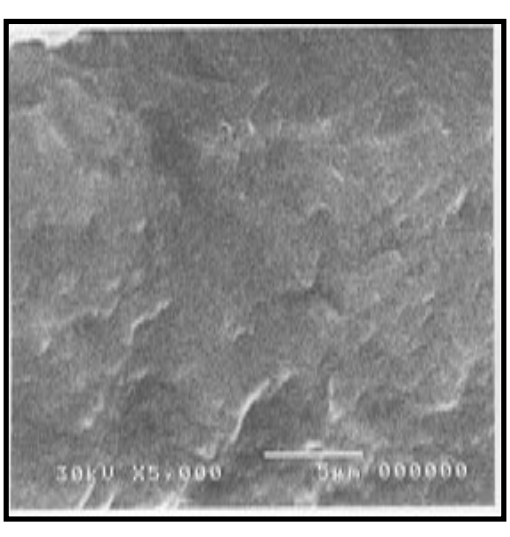

PLST/CMC (80\%/20\%)

Fig. 9. SEM micrographs of the surface fractures of unirradiated pure PLST and the PLST/CMC blends with different composition ratios 
Military Technical College Kobry El-Kobbah, Cairo, Egypt

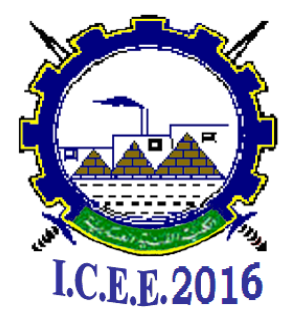

$8^{\text {th }}$ International Conference on Chemical \& Environmental Engineering

19-21 April 2016

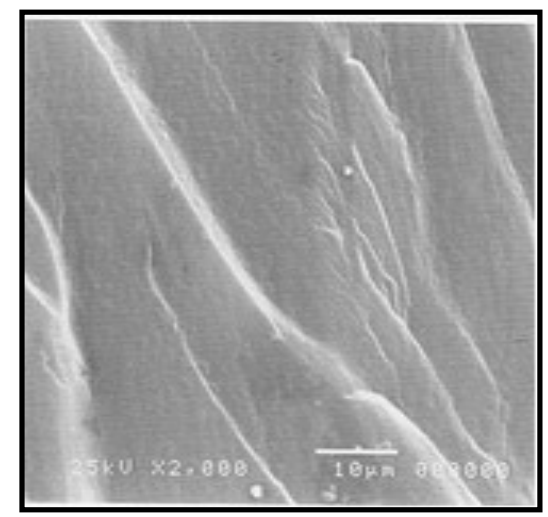

PLST/CMC (90\%/10\%) 10 kGy

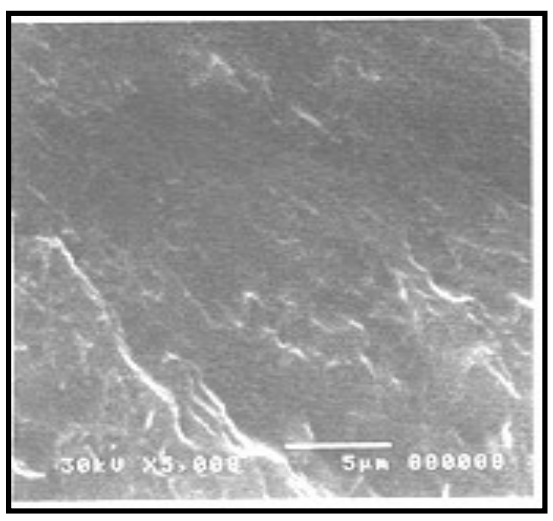

PLST/CMC (90\%/10\%) 50 kGy

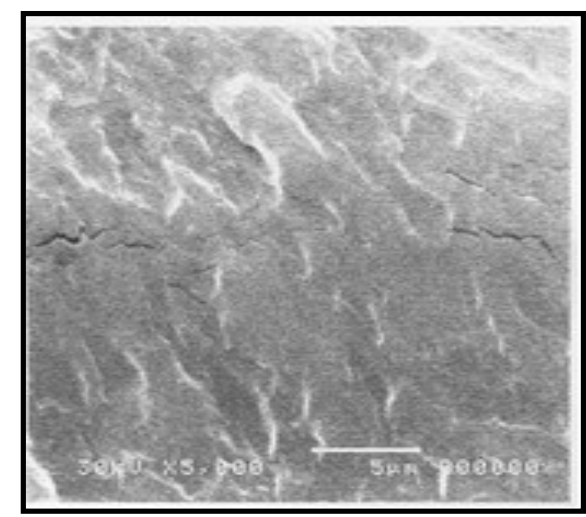

PLST/CMC $(80 \% / 20 \%) \quad 10$ kGy

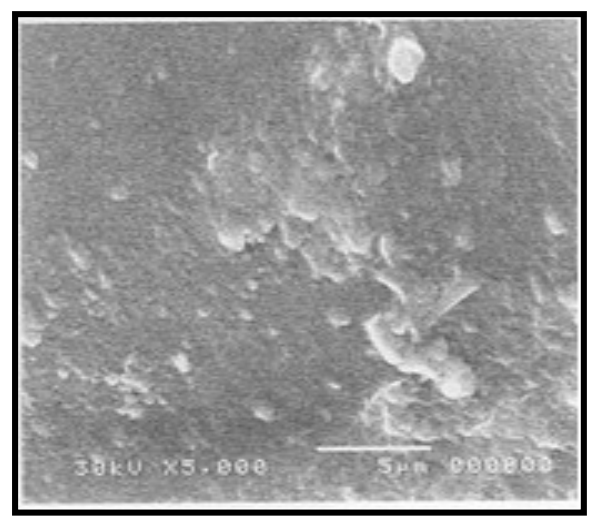

PLST/CMC- $(80 \% / 20 \%) 50$ kGy 
Military Technical College Kobry El-Kobbah, Cairo, Egypt

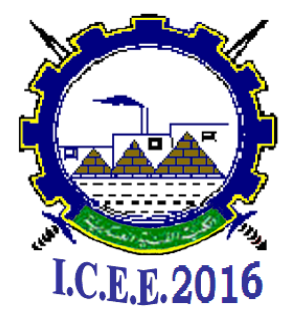

$8^{\text {th }}$ International Conference on Chemical \& Environmental Engineering

$19-21$ April 2016

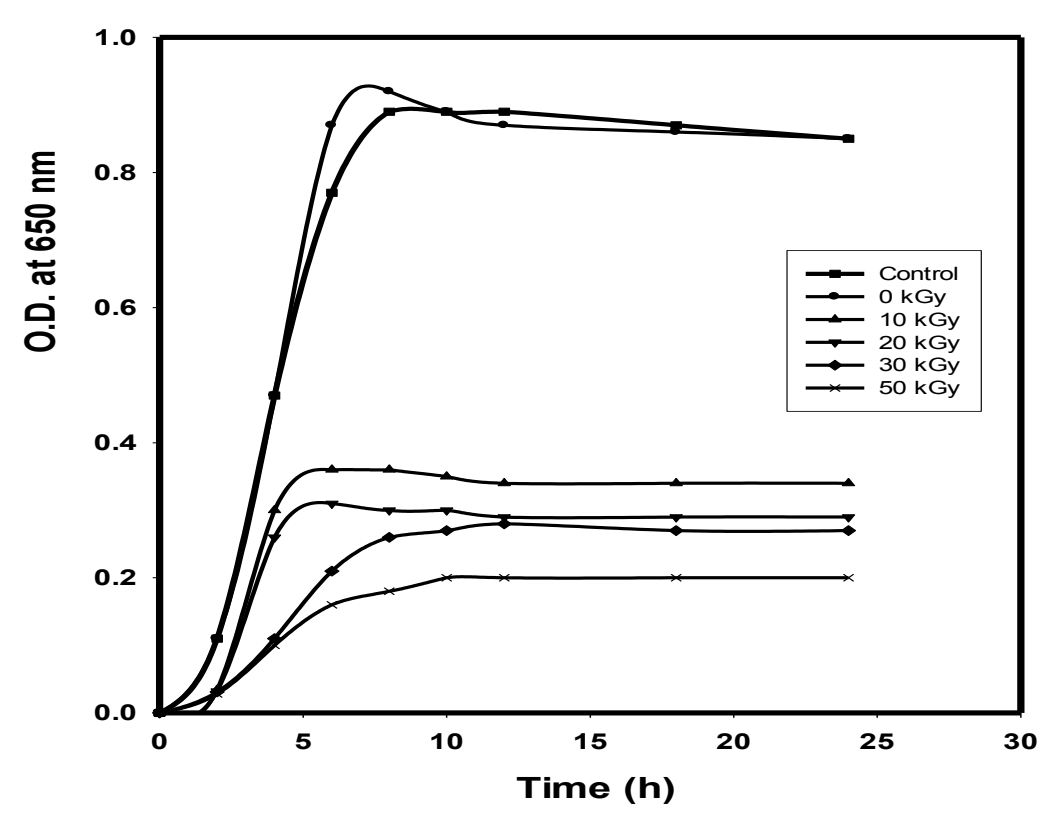

Fig. 11. Inhibition of $E$. coli growth by an irradiated PLST/CMC/chitosan $(80 \% / 15 \% / 5 \%)$ solution as determined by the optical density (OD).

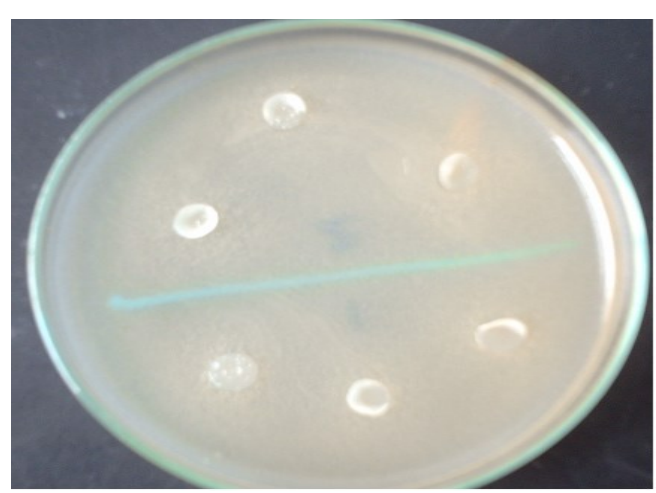

$\mathbf{A}$

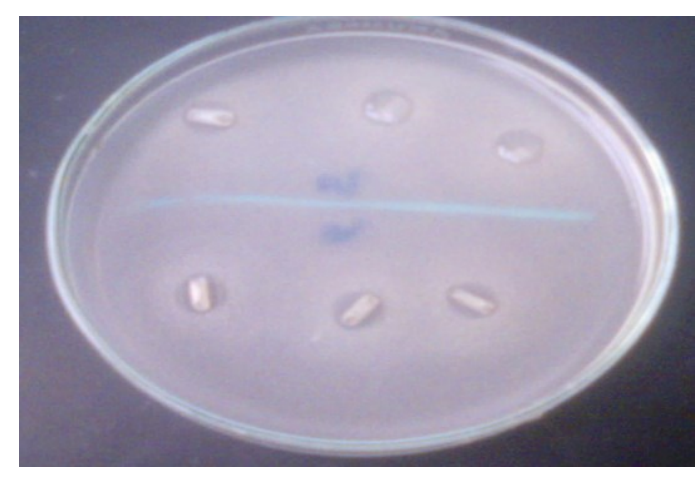

B

Fig. 12. Photographs showing the inhibition of $E$. coli growth by an unirradiated PLST/CMC/chitosan solution (A) and $30 \mathrm{kGy}$-irradiated PLST/CMC/chitosan (B). 
Military Technical College Kobry El-Kobbah, Cairo, Egypt

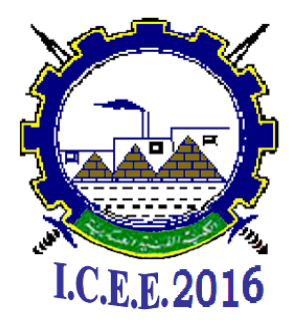

$8^{\text {th }}$ International Conference

on

Chemical \& Environmental Engineering

19-21 April 2016

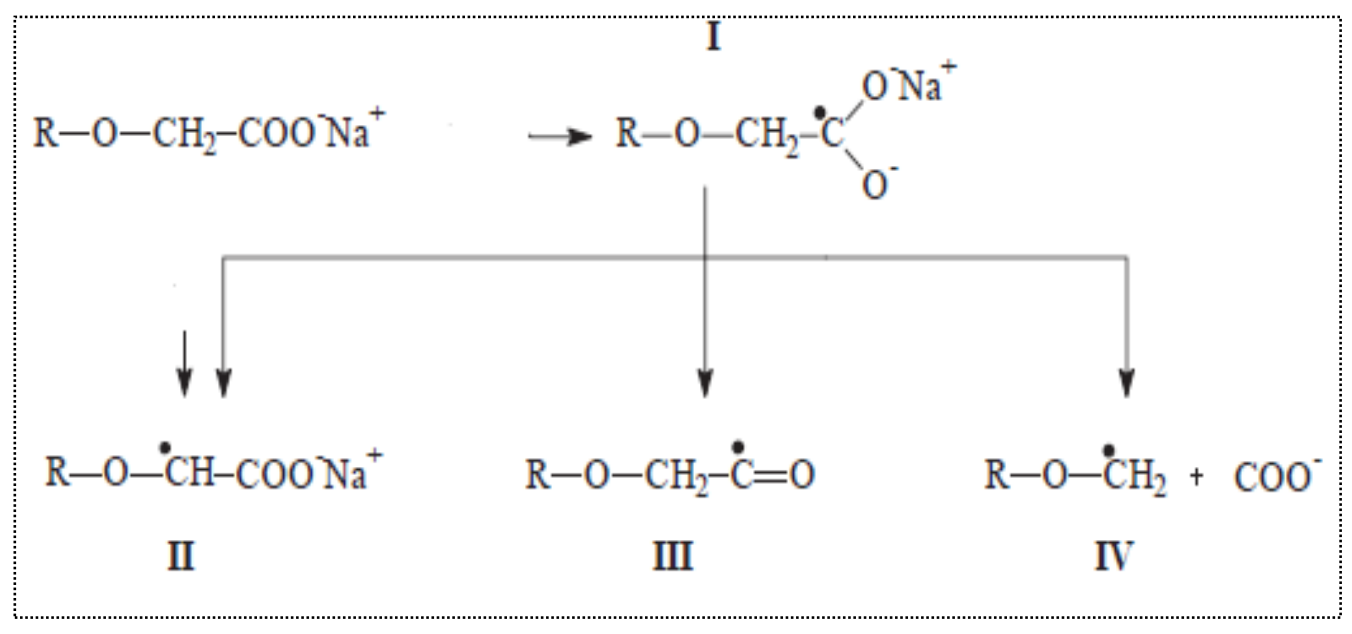

Scheme 1. Proposed radicals that formed on the side chain of CMC due to ionizing radiation $[22]$.

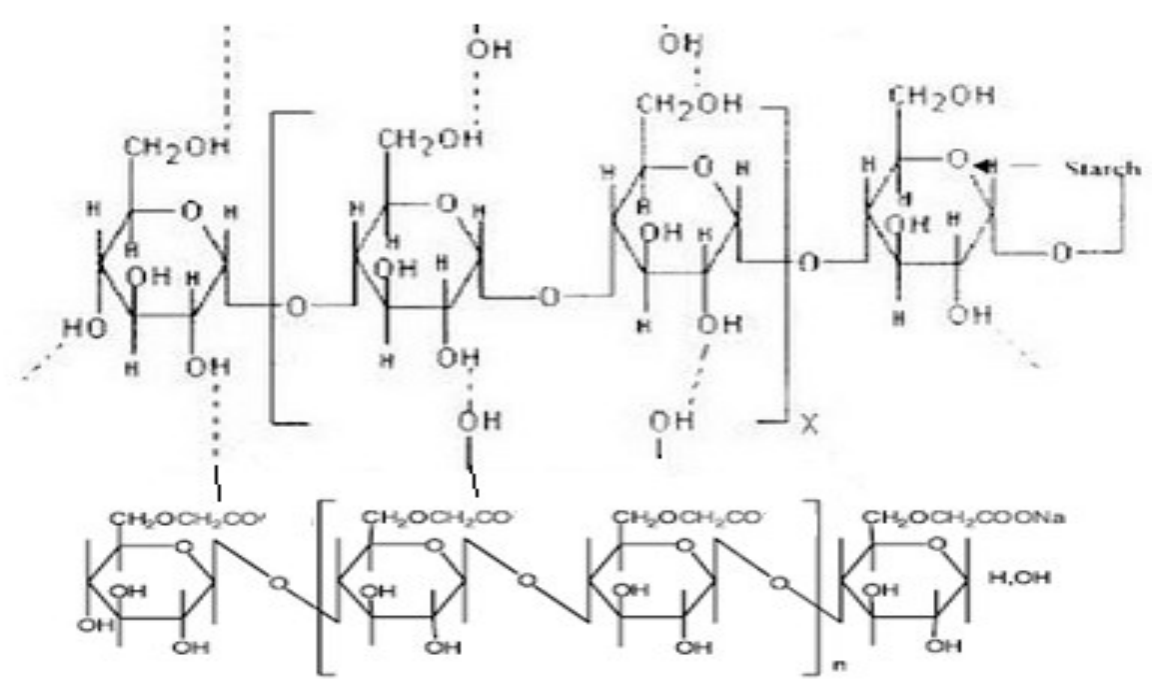

